\title{
El último eslabón del régimen de transición pensional
}

\section{The last link in the transitional pension regime}

\section{RESUMEN}

El presente artículo propende por caracterizar -con el apoyo de la hermenéutica jurídica aplicada a la jurisprudencia- las generalidades del régimen de transición pensional, para luego profundizar su recuperación para los beneficiarios del régimen de transición pensional por tiempo de servicios cotizados y finalmente, la condición de equivalencia, la cual se analiza en el contexto jurídico que la fundamenta.

\section{PALABRAS CLAVE}

Régimen de transición pensional, Pérdida de la pensión, Recuperación del régimen de transición pensional, Beneficiarios del régimen de transición, Condición de equivalencia del ahorro.

\section{ABSTRACT}

This article aims to characterize with the support of legal interpretation applied in this case, the generalities of the regime in transitional pension, to then deepen in the benefits of the transition pension regimen for the time of services quoted and finally the condition of equivalence, which is analyzed in a judicial content which fundaments it.

\section{KEYWORDS}

Transitional pension regime, Loss of the pension, Recovery of the regime of transitional pension, Benefits of the transitional regime, Conditions of equivalence saving.

\section{ÁNGELA BIBIANA GÓMEZ CONTRERAS}

Abogada egresada de la Universidad Javeriana. Maestría en Gestión de Fondos de la Universidad de Alcalá de Henares. Especialización Comercial y Sociedades Universidad Javeriana y Financiero Universidad de los Andes. Experiencia como responsable del área legal de varios fondos de pensiones por aproximadamente 15 años. angela.gomez@usa.edu.co 


\section{INTRODUCCIÓN}

En el ámbito constitucional el objeto y alcance del régimen de transición ha suscitado diversos debates académicos, poniendo de presente la estrecha relación entre la aplicación de esta figura y varios postulados constitucionales, entre otros: a) el principio de progresividad y condición más beneficiosa (Uprimny \& Guarnizo, 2008), b) el principio de sostenibilidad fiscal y el Estado Social de Derecho (Vinueza, 2012), c) el control constitucional y modelo económico (Uprimny \& Rodríguez, 2005) y d) los derechos adquiridos, las meras expectativas y las expectativas legítimas (Sentencias: C-613 de 1996; C-596 de 1997; C-789 de 2002; C-1024 de 2004; C-754 de 2004; T-818 de 2007; T-180 de 2008; T-398 de 2008; T-583 de 2010; SU-062 de 2010 y SU-130 de 2013).

Dentro de este contexto, el presente artículo pretende lograr una aproximación constitucional, legal y reglamentaria en el tema de la recuperación del régimen de transición pensional para la categoría de beneficiarios por tiempo de servicios cotizados, que se vincularon o trasladaron al régimen de ahorro individual con solidaridad, para quienes se exige, no solo permanecer en el régimen de prima media con prestación definida (Sentencia T-566 de 2009) y trasladar todo el ahorro realizado, sino además, el cumplimiento de una condición de equivalencia del ahorro.

Esta condición fue creada jurisprudencialmente en el año 2002 (Sentencia C-789 de 2002), pero en el año 2003 con ocasión de la expedición de la Ley 797 de 2003 se desequilibró por afectación de los factores de comparación que la fundamentaban (Ley 797 de 2003), los cuales, aunque se corrigieron legislativamente en el año 2008 (Decreto 3995 de 2008) solamente en año 2010 (Sentencia SU-062 de 2010, expediente T-2021850; CE006 de 2010) lograron alguna efectividad, mediante la definición de una fórmula de equivalencia clara y precisa y la creación de la opción para el afiliado, de aportar voluntariamente cualquier diferencia que arrojare su aplicación.

Para desentrañar la condición de equivalencia del ahorro se acudió como fuente primaria a la interpretación jurisprudencial que la Corte Constitucional ha venido realizando para el régimen de transición pensional en general, por la vía del control abstracto y por la vía del control concreto, mediante revisión excepcional de sentencias de tutela.

De ahí que frente a la condición de equivalencia, sea factible plantear las siguientes preguntas: ¿Cuál es su génesis?, ¿qué filosofía la inspiró?, ¿en qué consiste y quiénes pueden acogerse a ella?, ¿cómo se aplica a casos concretos? y algunas reflexiones finales a partir de las cifras actuales en materia de traslados suministradas por Asofondos*

\footnotetext{
* Asociación Colombiana de Administradores de Fondos de Pensiones y Cesantías, 2013, Información suministrada por Asofondos al grupo CREAR de la Universidad Sergio Arboleda para fines académicos. En total hasta el año 2012, el administrador del régimen de prima media con prestación definida radicó a las administradoras del régimen privado 102.663 solicitudes de traslado, de las cuales fueron efectivas solamente 100.751 que están a menos de 10 años de pensión y de estas, para el año 2012, 1.056 personas corresponden a la aplicación de los criterios de la Sentencia SU-062 de 2010.
} 
debidamente discriminadas de febrero de 2003 a 31 de julio de 2012.

\section{Generalidades del régimen de transición}

Buscando corregir la situación pensional de Colombia común en cierta forma a América Latina, en 1993 se adoptó una reforma estructural al sistema pensional, inspirada en el modelo chileno (Lora \& Pagés, 2000), dentro de la cual, el régimen de transición se erige como un aspecto central, por cuanto a más de constituir el mecanismo de protección por excelencia frente al cambio regulatorio, al permitir el reconocimiento de determinadas condiciones preferenciales de los regímenes pensionales anteriores a la vigencia de la Ley 100 de 1993, en favor de determinados grupos calificados por edad o servicios cotizados (Ley 100 de 1993).

El efecto económico de la aplicación del régimen de transición en el rubro del pasivo pensional público en términos porcentuales del PIB, se ha incrementado considerablemente, de forma que estudios económicos como el de ANIF (Clavijo \& Vera, 2010) presentan cifras alarmantes proyectando aumento del costo fiscal por pensiones en un 4,5\% del PIB para el período 2010-2014, que de materializarse el traslado masivo de afiliados de los fondos privados al público, podrían incrementar el pasivo pensional neto del $120 \%$ del PIB al 140 del PIB.

La Ley 100 de 1993 introdujo en Colombia un modelo paralelo (Ley 100 de 1993), que permitió la coexistencia del sistema público, de- bidamente modificado, junto con uno nuevo de carácter privado, basado el primero en la contribución a un fondo común y la relación intergeneracional de sus cotizantes y beneficiarios y; el segundo, en el ahorro y capitalización individuales con el apoyo de seguros previsionales y garantías estatales, teniendo en mente el generoso plazo de 30 años para la transición, como lo evidencia la exposición de motivos de la Ley 100 de 1993 (Holzmann, Palmer \& Uthoff, 2008, p. 530).

La experiencia en América Latina en materia de traslado entre regímenes de beneficio definido a contribución definida, esto es, entre prima media al ahorro individual, permite a algunos estudiosos afirmar que el déficit previsional no solo depende de la magnitud de la deuda pensional en sí, sino también de la dinámica de entrada y salida de beneficiarios a los regímenes, factor este último que corresponde, en algunos casos a la reconversión de una deuda de un sistema a otro (Mesa-Lago, 2004).

En Colombia la Corte Constitucional legitimó la existencia del régimen de transición en varios argumentos básicamente, la igualdad, proporcionalidad y protección frente al cambio normativo (Sentencias de tutela: T-572 de 2011, expedientes T-2.953.968, T-2.997.472, T-2.997.197 y T-2.952.152; Sentencia T-335 de 2011; Sentencia T-351 de 2010, expediente T-2.509.461; Sentencia T-618 de 2010, expediente T-2538309; Sentencia T-1014 de 2004, expediente T-936697; Sentencia T-235 de 2002, expediente T-471948). 
Como se desprende de la lectura del inciso segundo del artículo 36 de la Ley 100 de 1993 y lo ha desarrollado la jurisprudencia (Sentencia C-789 de 2002, expediente D-3958; Sentencia T-1014 de 2004, expediente T-936697), el legislador estableció el régimen de transición en favor de dos categorías de trabajadores que, al momento de entrar en vigor dicha Ley, esto es el $1^{\circ}$ de abril de 1994, cumplieran con determinados requisitos, estas categorías son: en primer lugar, los hombres que tuvieran más de $\mathbf{4 0}$ años; en segundo lugar, las mujeres mayores de 35 años y; en tercer lugar, los hombres y las mujeres que, independientemente de su edad, tuvieran 15 o más años de servicios cotizados.

Las categorías genéricamente pueden clasificarse en dos, la primera, los beneficiarios del régimen de transición por edad, y, la segunda, beneficiarios del régimen de transición por tiempo de servicios cotizados. En cuanto a los beneficios derivados de la aplicación del régimen de transición, señala literalmente el artículo 36 de la Ley 100 de 1993, que son la edad para acceder a la pensión de vejez, el tiempo de servicio o el número de semanas cotizadas y el monto de la pensión de vejez, temas que jurisprudencialmente también han suscitado controversia.

\section{Precisiones}

(।) El señalamiento de edades diferentes según el sexo como requisito para ser beneficiario del régimen de transición, en el caso concreto, mujeres con 35 o más años y hombres con 40 o más años, a la fecha de vigencia del sistema general de pensiones, no viola el principio constitucional de igualdad (Sentencia C-410 de 1994, expediente D-517).

(II) El aumento de las edades para acceder a la pensión de vejez a partir del año 2014, dentro del régimen de prima media con prestación definida, de 57 para mujeres y 62 para hombres no es caprichoso ni irrazonable sino que a juicio de la Corte Constitucional encuentra soporte en el crecimiento de la expectativa de vida de los colombianos (Sentencias C-126 de 1995, D-616, D-617 y D-625).

(III) Conforme lo ha sostenido la Corte Constitucional, el régimen de transición es un instituto jurídico propio de la prestación denominada pensión de vejez, que opera dentro del régimen de prima media con prestación definida del Sistema General de Pensiones previsto en la Ley 100 de 1993 (Sentencia C-596 de 1997, expediente D-1679; Sentencia C-623 de 2004, expediente D-493).

(IV) Conforme la metodología dispuesta por el artículo 33 de la Ley 100 de 1993, las semanas se componen de siete (7) días por lo cual, quince (15) años de servicios equivalen a 750 semanas cotizadas.

(v) La vigencia del Sistema General de Pensiones conforme lo señala el artículo 151 de la Ley 100 de 1993 , es $1^{\circ}$ de abril de 1994 para nivel nacional y a más tardar 30 de junio de 1995 para el nivel territorial. 
Situación especial de los afiliados beneficiarios del régimen de transición por tiempo de servicios cotizados

El traslado voluntario al régimen de ahorro individual con solidaridad no conlleva pérdida absoluta del régimen de transición

Desde un comienzo la Ley 100 de 1993 reguló en el artículo 36 literales 4 y 5 la posibilidad de traslado entre regímenes para los beneficiarios del régimen de transición tanto por edad como por tiempo de servicios cotizados, bajo la consideración en ambos casos, que para la aplicación del régimen de transición era necesario no renunciar voluntariamente al régimen de prima media con prestación definida y que este último acto traía consecuencias diferentes en uno y otro caso, justificadas jurisprudencialmente a partir de las Sentencias C-789 de 2002 y C-1024 de 2004.

Para el caso de los beneficiarios por tiempo de servicios cotizados, la Corte precisó que ni el inciso $4^{\circ}$, ni el inciso $5^{\circ}$ del artículo 36 de la Ley 100 de 1993, se referían a la tercera categoría de trabajadores, es decir, a quienes contaban a 10 de abril de 1994 con 15 años de servicios cotizados.

En tal sentido aclaró que los beneficiarios de transición por tiempo de servicios cotizados, no quedaban expresamente excluidos del régimen de transición al trasladarse al régimen de ahorro individual con solidaridad y tampoco quedaban excluidos quienes se cambia- ron al régimen de prima media y luego regresaron al de ahorro individual.

Lo anterior conforme al principio de proporcionalidad, pues resultaría violatorio del reconocimiento constitucional al trabajo que quienes hubieren cumplido con el $75 \%$ o más del tiempo de labores necesario para acceder a la pensión, a la entrada en vigencia del sistema, terminen perdiendo las condiciones en las que aspiraban a recibir su pensión.

Por lo anterior al declarar la exequibilidad del artículo 36, la Corte precisó que los incisos 4 y 5 , lo eran bajo el entendido que no se aplican a las personas que tenían 15 años o más de trabajo cotizados al momento de entrada en vigor del Sistema General de Pensiones.

No obstante los anteriores lineamientos constitucionales, como lo ha reconocido la propia Corte Constitucional (Acción de tutela, Sentencia T-232 de 2011) ha sido a partir de situaciones concretas resueltas mediante tutela que se ha desarrollado el tema del traslado entre regímenes para beneficiarios del régimen de transición, llegando incluso a igualar su efecto para todos los beneficiarios tanto por edad como por tiempo de servicios cotizados, por la vía de considerar el derecho al régimen de transición per se como un derecho adquirido para quienes cumplieran cualquiera de las condiciones para hacer parte de él (Sentencia T-818 de 2007, expediente T-1635513; Sentencia T-064 de 2011, expediente T-2.798.192). 
La posición anterior ha coexistido entonces, con aquella que sostiene que en los términos del artículo 36 incisos 4 y 5 de la Ley 100 de 1993, la protección que se otorga a los beneficiarios de transición por edad, se extingue cuando se escoge, inicialmente o por traslado, el régimen de ahorro individual y no se recupera por el cambio posterior que se haga al régimen de prima media con prestación definida (Acción de tutela, Sentencia T-168 de 2009), no obstante, con ocasión de la reciente Sentencia de Unificación SU-0013 de 2013 se ha erigido como única.

Respecto a los beneficiarios de transición por tiempo de servicios cotizados, es decir, hombres o mujeres, que a la vigencia del sistema general de pensiones, tenían 15 o más años de servicios cotizados, la jurisprudencia ha sido uniforme y reiterativa en justificar su posición especial frente a la aplicación del régimen de transición, incluso para el caso de regímenes especiales (Acción de constitucionalidad, Sentencia C-794 de 2009).

La afirmación en el sentido que los incisos 4 y 5 del artículo 36 de la Ley 100 de 1993 únicamente le son aplicables a las mujeres y a los hombres que, al entrar en vigencia el estatuto de seguridad social, tenían como mínimo 35 y 40 años de edad respectivamente, quienes el acogerse o trasladarse al régimen de ahorro individual, pierden los beneficios que consagra el régimen de transición, contenidos en algunas sentencias (Acción de tutela, Sentencia T-317 de 2011) resulta hoy la única posición válida.
Téngase en cuenta que ya en Sentencia Unificadora la Corte Constitucional del año 2010 (Acción de unificación, Sentencia SU-062 de 2010), había aclarado que el traslado entre regímenes deja de ser una simple cuestión legal y adquiere relevancia constitucional por estar en juego un derecho fundamental, dada la repercusión que tiene en el goce efectivo de la pensión de vejez.

No hay lugar a la aplicación del plazo de permanencia mínimo ni del plazo de carencia previstos en el artículo 2 de la Ley 797 de 2003

El artículo 2 de la Ley 797 de 2003 modificó el literal e) del artículo 13 de la Ley 100 de 1993, mediante la creación de un período de gracia para el traslado entre regímenes hasta el 29 de enero de 2004, vencido el cual estableció una prohibición nueva en materia de traslados entre regímenes pensionales, creando un período de carencia, en virtud de la cual, los afiliados no podrían trasladarse de régimen cuando le faltaren diez (10) años o menos para cumplir la edad para tener derecho a la pensión de vejez. Adicionalmente la norma amplió el plazo mínimo de permanencia para traslado entre regímenes, de tres (3) a cinco (5) años.

Si bien la norma demandada no aplica exclusivamente la situación de los beneficiarios de transición por tiempo de servicios cotizados, indirectamente los afectaba, porque, ni ellos ni los demás afiliados podrían trasladarse de régimen cuando les falten 10 años o menos 
para cumplir la edad que requieren para adquirir la pensión de vejez, por lo cual el cambio normativo implicaría para ellos el no poder hacer uso de los beneficios previstos en la Sentencia C-789 de 2002.

La Corte Constitucional mediante Sentencia C-1024 de 2004, se pronunció a favor de la constitucionalidad del artículo 2 de la Ley 797 de 2003, apoyada en la consideración que constituye una medida adecuada, proporcionada y necesaria que busca un fin constitucionalmente legítimo, como es el de impedir la descapitalización del fondo común del régimen solidario de prima media con prestación definida, que implicaba que personas que no contribuyeron y que por tanto no fueron tenidas en cuenta para los cálculos actuariales se beneficiaran de este, cuando estén próximas a edad de pensión y ello resulta contrario al principio constitucional de la equidad y eficiencia, planteamiento este que también se predica respecto de las utilidades del régimen de ahorro individual con solidaridad.

No obstante aclaró la Corte en la sentencia en cita, que este artículo no era aplicable a los beneficiarios por tiempo de servicios cotizados, es decir, hombres o mujeres que a $1^{\circ}$ de abril de 1994 o fecha de vigencia del Sistema General de Pensiones tuvieren cotizados 15 o más años de servicios. De igual forma al precisar que el traslado en estas condiciones podía realizarse en cualquier tiempo eliminó la barrera del plazo mínimo de permanencia.
Traslado al régimen de prima media con prestación definida para recuperar el régimen de transición procede en cualquier tiempo

Consecuencia directa del tratamiento especial de los beneficiarios del régimen de transición por tiempo de servicios cotizados, es la posibilidad de regresar o trasladarse al régimen de prima media con prestación definida en cualquier momento para recuperar el régimen de transición.

La Corte al declarar exequible el artículo 2 de la Ley 797 de 2003, en lo relativo al año de gracia y período de carencia para quienes les faltaren 10 o menos años para cumplir edad de pensión de vejez, lo hizo bajo el entendido que las personas que reúnen las condiciones del régimen de transición previsto en el artículo 36 de la Ley 100 de 1993 y que habiéndose trasladado al régimen de ahorro individual con solidaridad, no se hayan regresado al régimen de prima media con prestación definida, pueden regresar a este último -en cualquier tiempo-, conforme a los términos señalados en la Sentencia C-789 de 2002 y sin consideración a la fecha en que entró a regir el artículo 2 de la Ley 797 de 2003 (Acción de constitucionalidad, Sentencia C-1024 de 2004).

Esta posibilidad de traslado en cualquier tiempo no es posible hoy para los beneficiarios del régimen de transición por edad como lo refiere la Sentencia de Unificación SU-130 de 2013, para quienes se aplica tanto el período mínimo de permanencia como el 
plazo de carencia de los 10 años anteriores a la edad de pensión.

Acreditado el cumplimiento de los supuestos de hecho y de derecho para la transición por tiempo de servicios cotizado, el beneficiario tiene derecho al traslado sin que le sean oponibles condiciones administrativas de otra índole

La condición de beneficiario del régimen de transición por tiempo de servicios debidamente acreditada habilita sin más condicionamientos su traslado al régimen de ahorro individual en cualquier momento y su recuperación dependerá del cumplimiento de la condición de equivalencia del ahorro. La única limitante que sería el hecho de que ya se le hubiera reconocido la pensión de vejez u otro beneficio pensional subsidiario por parte de alguna de las entidades de previsión social, como lo ha sostenido la jurisprudencia en la ya citada Sentencia T-317 de 2011.

No constituye limitante legítima tampoco, el trámite interno de la historia laboral ni situaciones como la múltiple vinculación sin definir (Sentencia T-317 de 2011, expediente T-2898627; Sentencia T-618 de 2010, expediente T-2538309).

\section{Génesis de la condición de equivalencia de aportes}

La Corte Constitucional sustentó la exequibilidad de los incisos 4 y 5 del artículo 36 de la Ley 100 de 1993 en diferentes argumentos (Acción de constitucionalidad, Sentencia
C-789 de 2002), entre ellos: (I) todo tránsito legislativo debe consultar parámetros de justicia y equidad, (II) la actividad del Estado está sujeta a principios de razonabilidad y proporcionalidad, (III) para que se consolide un derecho es necesario que antes que se produzca el tránsito legislativo se reúnan todas las condiciones necesarias para adquirirlo, con lo cual acogió la posición sobre derechos adquiridos asumida por la Corte en las Sentencias C-147 de 1997 y C-596 de 1997, y (IV) en materia de expectativas o expectativas legítimas, prevalece la facultad configurativa del legislador aunque limitada dada la condición de irrenunciabilidad del derecho de la seguridad social.

En términos de la sentencia en cita, a quienes habían cotizado por un período de 15 años o más al tiempo de entrada en vigencia del Sistema General de Seguridad Social de Pensiones y se hubieren cambiado al régimen de ahorro individual, regresando con posterioridad al de prima media con prestación definida, se les aplicarán las condiciones de tiempo de servicios, edad y monto de la pensión, consagradas en el régimen anterior, siempre y cuando:

a) "Al cambiarse nuevamente al régimen de prima media, se traslade a él todo el ahorro que habían efectuado al régimen de ahorro individual con solidaridad, y

b) Dicho ahorro no sea inferior al monto total del aporte legal correspondiente en caso que hubieren permanecido en el régimen de prima media".

Vía jurisprudencial la sentencia en cita intro- 
dujo el concepto de equivalencia del ahorro a partir de las siguientes premisas: (I) obtener el equilibrio o igualdad entre los recursos que tuvieren los beneficiarios del régimen de transición por servicios cotizados obtenidos en el régimen de ahorro individual con solidaridad y los que hubiere alcanzado en el régimen de prima media con prestación definida si nunca se hubieren trasladado de este último, (II) evitar la descapitalización del régimen de prima media con prestación definida.

En cuanto a parámetros de aplicación la sentencia definió para el régimen de ahorro individual con solidaridad, los ahorros acumulados en la cuenta de ahorro individual del afiliado $y$, para el régimen de prima media con prestación definida, el aporte legal correspondiente.

Si bien la expresión "el ahorro efectuado" tiene claro contenido en la propia Ley 100 de 1993 , en el sentido que corresponde a la parte del aporte que se destina exclusivamente a la cuenta de ahorro individual descontado el concepto de primas y seguros (Ley 1328 de 2009) y respecto de la cual el afiliado devenga los rendimientos del fondo; la expresión "aporte legal correspondiente en caso que hubieren permanecido en el régimen de prima media con prestación definida" es indeterminada pues no tiene un contenido expreso en la propia ley, ni la Corte se lo atribuye en la misma sentencia.

La equivalencia del ahorro así prevista tenía aplicabilidad en los términos del original ar- tículo 20 de la Ley 100 de 1993, por cuanto la distribución porcentual para el riesgo de vejez era similar en ambos regímenes.

Sin embargo, en el artículo 7 de la Ley 797 de 2003 estableció una diferencia al crear exclusivamente para el régimen de ahorro individual con solidaridad un aporte especial destinado a un fondo de garantía de pensión mínima del 1,5\%, sin correlación alguna en el régimen de prima media con prestación definida, con lo cual el aporte para vejez en este último siempre resultaría mayor.

En un intento por reglamentar el artículo 2 de la Ley 797 de 2003, se expidió el Decreto 3800 de 2003 , el mismo 29 de enero de 2003 (Decreto 3800 de 2003) estableciendo la aplicación del régimen de transición para los beneficiarios por servicios cotizados, quienes podrían pensionarse con el régimen de transición previsto en el artículo 36 de la Ley 100 de 1993, siempre y cuando cumplieran dos condiciones: a) que al cambiarse nuevamente al régimen de prima media con prestación definida, se traslade a este el saldo de la cuenta de ahorro individual del régimen de ahorro individual con solidaridad, y b) dicho saldo no resultare inferior al monto total del aporte legal para el riesgo de vejez, correspondiente en caso de que hubieren permanecido en el régimen de prima media, incluyendo los rendimientos que se hubieran obtenido en este último. Esta disposición modificó los factores a considerar en la condición de equivalencia por la vía de incorporar la rentabilidad, pero no resolvió el problema, sino que lo agravó de forma 
que llevó a la jurisprudencia a incorporar en casos concretos, el análisis sobre la afectación de la equivalencia del ahorro frente a la estabilidad financiera del sistema, la descapitalización del fondo común y el beneficio obtenido a partir de aportes de otros (Acción de tutela, Sentencia T-347 de 2008).

Legislativamente se buscó corregir la anterior situación con la expedición del Decreto 3995 de 2008 que de forma expresa incorporó al cálculo el concepto de garantía de pensión mínima.

En presencia de varias situaciones particulares de desequilibrio vía revisión de tutela la Corte varió considerablemente su posición original, y mediante sentencia (Acción de tutela, Sentencia T-818 de 2007) llegó a considerar que la condición de equivalencia del ahorro prevista en la Sentencia C-789 de 2002 devino en imposible por razón del cambio legislativo del artículo 2 de la Ley 797 de 2003, razón por la cual y dada la condición "disyuntiva" que define los beneficiarios del régimen de transición, tanto aquellos que lo son por edad, como aquellos que lo son por tiempo de servicios cotizados, podrían recuperarlo. Para lo cual bastaría el traslado al régimen de prima media con prestación definida en cualquier tiempo y el traslado de los ahorros realizados en el régimen de ahorro individual con solidaridad, sin sujeción a ninguna condición en materia de equivalencia del ahorro.

Recientemente vía tutela, la Corte Constitucional reiteró la anterior posición, pero le in- trodujo una modificación (Acción de tutela, Sentencia T-449 de 2009) al considerar que solo los beneficiarios del régimen de transición por tiempo de servicios cotizados podían recuperar el régimen de transición, nuevamente sin sujeción a condición de equivalencia del ahorro. En línea se ubican algunas Sentencias, entre ellas T-320 de 2010 y T-232 de 2011.

Respecto al valor de las sentencias en sede de revisión la Corte Constitucional mediante sentencia que declaró la exequibilidad del artículo 33 del Decreto 2591 de 1991 (Acción de constitucionalidad, Sentencia C-018 de 1993) precisó que la jurisprudencia de la Corte debe ser universal, coherente y consistente para realizar el principio de igualdad material, en virtud del cual situaciones similares deben recibir igual tratamiento y también por razones de certeza en el tráfico jurídico. Estos atributos requieren de la existencia de un mecanismo de unificación.

Señala la Corte en la sentencia en cita que:

“(..) Mal haría la Corte en contribuir a la didáctica constitucional mediante sentencias contradictorias, que antes que educar desorientan y crean confusión. Para ello entonces se creó el mecanismo unificador regulado en la norma acusada".

Y en otro aparte dispuso:

"Las decisiones de tutela de la Corte Constitucional no se limitan a resolver 
el conflicto particular sino que tienen un efecto pedagógico que afianza y arraiga el papel rector de la Constitución en el arbitraje social y la regulación de la vida en comunidad. La jurisprudencia constitucional de derechos fundamentales cumple así una triple función legitimadora: es marco de referencia para las autoridades y los particulares, asegura la efectividad de los derechos, principios y deberes consagrados en la Constitución y genera el consenso social indispensable para la convivencia pacífica".

El cumplimiento de la condición de equivalencia del ahorro fue estudiado por la Corte Constitucional en la Sentencia SU-062 de 2010, mediante la cual consideró que con la expedición del Decreto Reglamentario 3995 de 2008, que estableció que el traslado de recursos del régimen de ahorro individual al régimen de prima media con prestación definida debía surtirse con inclusión del porcentaje correspondiente al aporte al Fondo de Garantía de Pensión Mínima, hizo posible su cumplimiento.

La Corte reiteró así la jurisprudencia establecida en las Sentencias C-789 de 2002 y C-1024 de 2004, señalando que solo algunas personas amparadas por el régimen de transición podrían regresar en cualquier tiempo, con el fin de pensionarse bajo las normas anteriores a esta, previo cumplimiento de la condición de equivalencia del ahorro.

Con la sentencia unificadora en cita, la Corte declaró adicionalmente, la nulidad de la Sentencia T-168 de 2009 y ajustó la jurisprudencia constitucional en materia de régimen de transición y condición de equivalencia, siendo su gran aporte la inclusión de un mecanismo para superar cualquier diferencia derivada del cálculo de la equivalencia del ahorro por factores de cualquier orden incluso diferentes a los contemplados en la fórmula jurisprudencial.

Fue así como creó la posibilidad de aportar voluntariamente cualquier diferencia que arrojare al cálculo de la condición de equivalencia por parte del beneficiario del régimen de transición por tiempo de servicios cotizados para hacer efectivo su derecho a recuperar el régimen de transición.

En el año 2011, el Consejo de Estado (Decreto 3800 de 2003-Consejo de Estado, Sala de lo Contencioso Administrativo, CP Gerardo Arenas Monsalve, Sentencia 6 de abril de 2011, radicación 1101-03-25-00, 200700054-00 1995-2) Sentencia C-086 de 2002, demanda de inconstitucionalidad contra los artículos 59 (parcial) 60 (parcial) 62, 63, 66, 68 (parcial), Magistrado Ponente Clara Inés Vargas, febrero 13 de 2002) a propósito de la demanda formulada contra el Decreto 3800 de 2003 , se pronunció decretando la nulidad de las expresiones "cumplan con los siguientes requisitos: (...) y b) Dicho saldo no sea inferior al monto total del aporte legal para el riesgo de vejez, correspondiente en caso que hubieren permanecido en el régimen de prima media, incluyendo los rendimientos que se hubieran obtenido en este último", así 
como del inciso final que dispone que "Para efectos de establecer el monto del ahorro de que trata el literal b) anterior no se tendrá en cuenta el valor del bono pensional" contenidas en el citado artículo del Decreto 3800 de 2003 que reglamentó el literal e) del artículo 13 de la Ley 100 de 1993.

Fundamentó su decisión el Consejo de Estado en la consideración, que el Gobierno Nacional excedió su potestad de reglamentación para la cumplida ejecución de las leyes con la expedición del Decreto 3800 de 2003, en la medida que al incluir dentro de los factores de equivalencia la inclusión del rendimiento que hubiere obtenido en el régimen de ahorro individual con solidaridad, colocó a quienes pretenden recuperar la transición en una condición casi imposible de cumplir, toda vez que el rendimiento en el fondo común siempre será mayor al rendimiento de las cuentas de ahorro individual.

Al reglamentar la forma de aplicación de régimen de transición, estableció condiciones adicionales a las previstas en la Ley 100 de 1993 para estos efectos.

De igual forma precisó el Consejo de Estado que las decisiones de la Corte Constitucional en materia de constitucionalidad no son susceptibles de reglamentación, por cuanto las primeras tienen efectos erga omnes al igual que las leyes y adicionalmente no tienen un carácter abstracto sino que pueden conllevar la modulación de los efectos mediante sentencias integradoras que responden a la necesidad de integrar el ordenamiento jurídico para que en cada caso resulte acorde con la Constitución Política.

En cuanto a la legitimidad de los fallos integradores de la Corte Constitucional, el Consejo de Estado precisó (Radicado 110103-25-00, 2007-00054-00 1995-2) que en determinados casos la simple exequibilidad de una norma resulta insuficiente, dada su imprecisión o la existencia de vacíos en esta, que generan como única alternativa para que la Corte cumpla su función constitucional, la expedición de una sentencia integradora del ordenamiento legal para lograr su eficacia.

Recientemente la Corte Constitucional mediante Sentencia Unificadora SU-130 de 2013 unificó la posición en torno al traslado del régimen de ahorro individual al régimen de prima media de los beneficiarios del régimen de transición, reiterando los criterios jurisprudenciales de las Sentencias C-789 de 2012 y C-1024 de 2004 en el sentido que solo los beneficiarios del régimen de transición por tiempo de servicios cotizados pueden regresar en cualquier tiempo al régimen de prima media con prestación definida para recuperar el régimen de transición, previo cumplimiento de la condición de equivalencia del ahorro en los términos de la Sentencia de Unificación SU-062 de 2010.

Filosofía que inspira la condición de equivalencia de aportes

Como lo evidencia la argumentación expuesta en la Sentencia de Unificación SU-062 de 2010, que corresponde a la interpretación 
actual en materia de régimen de transición y condición de equivalencia del ahorro, la opción de pagar la diferencia entre el saldo del ahorro de la cuenta de cada afiliado y el monto del aporte legal en caso que hubiere permanecido en el régimen de prima media con prestación definida, surge del tratamiento legal frente al conflicto por desequilibrio entre los aportes del régimen de prima media con prestación definida y el régimen de ahorro individual con solidaridad, para el caso de las pensiones de vejez por alto riesgo para salud.

En efecto, la Corte Constitucional en materia de pensión por actividades de alto riesgo para la salud privilegió la efectividad de pensionarse bajo regímenes especiales (Acción de constitucionalidad, Sentencia C-030 de 2009), citando tangencialmente la situación de los afiliados beneficiarios del régimen de transición que quisieran obtener su efectividad, respecto de quienes señaló que por tratarse de insalvable la imposibilidad de realizar un aporte voluntario de recursos adicionales necesarios para evitar que el monto del ahorro acumulado en sus cuentas no coincida con el aporte legal que hubiera correspondido en caso que permanecieran en el régimen de prima media con prestación definida.

La efectividad del derecho a cambiar de régimen pensional dentro del marco constitucional y legal vigente depende de que este pueda ser ejercido sin trabas insalvables. Uno de estos obstáculos es precisamente impedir que el interesado aporte voluntariamente los recursos adicionales en el evento de que su ahorro en el régimen de ahorro individual sea inferior al monto del aporte legal correspondiente en caso de que hubiere permanecido en el régimen de prima media con prestación definida. Esta barrera es salvable si el interesado aporta los recursos necesarios para evitar que el monto de su ahorro, al ser inferior en razón a rendimientos diferentes o a otras causas, sea inferior al exigido. Esto no solo es necesario dentro del régimen general, sino también en los regímenes especiales con el fin de conciliar el ejercicio del derecho del interesado en acceder a la pensión y el objetivo constitucional de asegurar la sostenibilidad del sistema pensional.

En el caso de las pensiones especiales de vejez en prima media por actividad de alto riesgo para la salud, corresponde por disposición legal el pago de cotización especial que es la prevista en la Ley 100 de 1993, más de 10 puntos a cargo del empleador y tal consideración sin ninguna otra adicional motiva el desequilibrio de los aportes entre prima media con prestación definida y ahorro individual con solidaridad.

Del aparte transcrito se infiere que es justamente la efectividad encaminada a obtener la aplicación efectiva del régimen de transición la que inspira y justifica la aplicación de la condición de equivalencia de aportes.

En concordancia con lo expuesto en el artículo 2 de la Ley 797 de 2003, dispone que en ningún caso a partir de la vigencia de dicha ley, podrán sustituirse semanas de cotización 
o abonarse semanas cotizadas o tiempo de servicios con el cumplimiento de otros requisitos distintos a la cotización efectivamente realizada o tiempo de servicios efectivamente prestados antes del reconocimiento de la pensión.

Como lo evidencia la exposición de motivos de la Ley 797 de 2003, el tiempo de servicio y las semanas de cotización exigidas para tener derecho a la pensión corresponderán al tiempo efectivamente prestado o cotizado, sin ninguna excepción, con miras a asegurar su financiación, por la vía de eliminar privilegios injustificados.

En qué consiste y quiénes pueden acogerse a la condición de equivalencia del ahorro

Según los lineamientos generales de la Corte Constitucional en Sentencia de Unificación SU-062 de 2010, recogiendo criterios de las Sentencias C-789 de 2002 y 1024 de 2004, los beneficiarios y las condiciones de aplicación son las siguientes:

(।) Para hacer efectiva la recuperación del régimen de transición respecto de los beneficiarios por tiempo de servicios cotizados deben cumplirse los siguientes requisitos: a) tener a 1 de abril de 1994, 15 años de servicios cotizados, b) trasladar al régimen de prima media con prestación definida todo el ahorro que hayan efectuado en el régimen de ahorro individual con solidaridad, c) que el ahorro hecho en el régimen de ahorro individual con solidaridad no sea inferior al monto total del aporte legal correspondiente en caso que hubieren permanecido en el régimen de prima media.

(II) Si al efectuar el traslado no se obtiene el cumplimiento de la condición de equivalencia de ahorros entre el régimen de ahorro individual con solidaridad y el de prima media con prestación definida en los términos de la Sentencia SU-062 de 2010, deberá ofrecerse la posibilidad al afiliado de aportar voluntariamente, en un plazo razonable, la diferencia entre el capital ahorrado en su cuenta de ahorro individual y el aporte legal correspondiente como si no se hubiera trasladado del régimen de prima media con prestación definida.

(III) Reconoce la sentencia que es posible que la equivalencia del ahorro no provenga actualmente de las reglas de distribución del aporte contenidas en la Ley 797 de 2003 sino que se derive de la diferencia de rentabilidad que producen los dos regímenes pensionales sobre los dineros aportados $u$ otros factores propios del mercado de valores y al hecho de que en el régimen de prima media con prestación definida se estructura a partir de un fondo común al paso que en el régimen de ahorro individual con solidaridad a partir de un patrimonio autónomo conformado por cuentas individuales propiedad de cada afiliado.

La aplicación de la condición de equivalencia del ahorro debe sujetarse a los señalamientos jurisprudenciales dados por la Sentencia de Unificación SU-062 de 2010 en concordancia con la Circular Externa 006 de 2011 
de la Superintendencia Financiera que desarrolló concretamente su fórmula de cálculo y, también dentro del marco general dado por la Sentencia SU-130 de 2013, que de forma particular abordó el interrogante de definir en qué casos es posible el traslado del régimen de ahorro individual con solidaridad al régimen de prima media con prestación definida para los beneficiarios del régimen de transición y; en qué casos dicho traslado se cumple conservando los beneficios del régimen de transición. A continuación un esquema del contenido de la Circular Externa 006 de 2011:
La fórmula prevista en la circular en referencia (Circular Externa de la Superintendencia Financiera de Colombia 006 de 2011) supone tomar la historia laboral del afiliado beneficiario de transición por servicios cotizados y aplicarle la rentabilidad de las reservas del ISS, que actualmente certifica la Superintendencia Financiera mes a mes de forma teórica, no obstante el agotamiento de reservas del ISS para vejez en el año 2004. Lo anterior supone implícitamente valorar la situación del afiliado como si hubiese estado en el ISS todo el tiempo y hubiera recibido los rendimientos de dicha entidad. copia de su cédula de ciudadanía. de traslado de afiliados que hubiere recibido, informando por cada afiliado, el número de semanas que hubiere cotizado el afiliado a 31 de marzo de 1994 o fecha de vigencia territorial del sistema.

Corresponde a la AFP verificar el cumplimiento de las exigencias contenidas en la Sentencia SU-062 de 2010 e informar al ISS, si el afiliado cumple o no los requisitos, teniendo en cuenta todo el tiempo cotizado al ISS y el tiempo de servicio prestado en entidades que no cotizaban. En caso que se cumplan los requisitos, corresponde a la AFP efectuar el cálculo de equivalencia del ahorro entre el régimen de prima media y el de ahorro individual, definiendo si la suma acumulada en la cuenta de ahorro individual es suficiente o equivalente a la que habría alcanzado el afiliado de haber continuado en prima media.

La AFP informará el resultado del proceso de validación al ISS, indicándole expresamente: (I) las solicitudes que fueron rechazadas por no cumplimiento de requisitos legales, (II) las solicitudes que fueron aprobadas por cumplimiento de requisitos legales o por cumplimiento del cálculo de equivalencia, (III) las solicitudes que cumpliendo el requisito de Ley, no cumplen con el requisito de traslado, en este caso señalando el valor de la diferencia que debería ser consignada por el afiliado.

Aquellas solicitudes que no cumplan el requisito de equivalencia deberán notificarse al afiliado mediante comunicación escrita que indicará; (I) el plazo de dos (2) meses de que dispone el afiliado para consignar a favor del ISS el valor de la diferencia a partir de la fecha de la comunicación respectiva, (II) la indicación de la entidad bancaria, el número de la cuenta, los medios de pago aceptados y el procedimiento para efectuar la consignación, (III) si la administradora de fondos de pensiones tiene establecido un plazo diferente de forma general que haya informado y justificado ante la Superintendencia Financiera de Colombia previamente. 


\section{REFLEXIONES FINALES}

- La condición de equivalencia del ahorro, se calificó para efectos de este artículo como "el último eslabón del régimen de transición", porque a pesar de estructurarse a partir de la aplicación de una fórmula de equivalencia y una opción de aporte voluntario por parte de los beneficiarios del régimen de transición por tiempo de servicios cotizados, es realmente una condición que de no cumplirse impide el reconocimiento y aplicación efectivos del régimen de transición.

- Pese a la uniformidad jurisprudencial en materia de recuperación de régimen de transición para los beneficiarios del régimen de transición por tiempo de servicios cotizados, existe incertidumbre jurídica real, derivada de la aplicación de la condición de equivalencia del ahorro para el lapso comprendido entre la Sentencia C-789 de 2002 y la Sentencia Unificadora SU-062 de 2010 desarrollada por la Circular 006 de 2010 de la Superintendencia Financiera de Colombia.

- Según las cifras suministradas por Asofondos, 1.056 afiliados, independientemente de su fecha de traslado al régimen de prima media con prestación definida, de la normativa vigente en esa época o de la posición de la Corte Constitucional vía sentencias de constitucionalidad, de revisión, de unificación o de tutela, hoy están sujetos indefectiblemente a los términos y condiciones de las Sentencias
Unificadoras SU-062 de 2010, dentro del marco de la Sentencia SU-130 de 2013.

- Las mismas cifras de Asofondos, dan cuenta que de febrero de 2003 a 31 de julio de 2012 solo se aprobaron 42.181 traslados con fundamento en la Sentencia SU-065 de 2010, cifra que pone en evidencia la magnitud del trabajo por realizar antes de la expiración del régimen de transición, que según las voces del Acto Legislativo 001 de 2005, se extenderá en forma extraordinaria hasta el año 2014.

- Los criterios definidos en la Sentencia de Unificación SU-062 de 2010, desarrollados en la Circular 006 de 2011 de la Superintendencia Financiera, deberán aplicarse hoy, a traslados realizados con anterioridad a la citada Sentencia Unificadora del año 2010 por los beneficiarios del régimen de transición por tiempo de servicios cotizados.

- Bajo los postulados de la seguridad jurídica, respecto al acto propio y confianza legítima desarrollados jurisprudencialmente para recuperación del régimen de transición, entre otras, por la Sentencia T-165 de 2010, deberán valorarse de forma individualizada las situaciones que, bajo criterios diferentes de la Corte Constitucional, impidieron la recuperación del régimen de transición por no cumplimiento de la condición de equivalencia o, lo permitieron sin su aplicación o con una interpretación diferente de la actual, afectando en el tiempo el goce efectivo del régimen de transición. 


\section{REFERENCIAS BIBLIOGRÁFICAS}

Acción de Constitucionalidad

Corte Constitucional. Sentencia C-018 de 1993, noviembre 25 de 1993.

Corte Constitucional. Sentencia C-410 de 1994, septiembre 15 de 1994.

Corte Constitucional. Sentencia C-126 de 1995, marzo 22 de 1995.

Corte Constitucional. Sentencia C-613 de 1996, noviembre 13 de 1996.

Corte Constitucional. Sentencia C-147 de 1997. M. P. Antonio Barrera Carbonell, marzo 19 de 1997.

Corte Constitucional. Sentencia C-596 de 1997. M. P. Vladimiro Naranjo Mesa, noviembre 20 de 1997.

Corte Constitucional. Sentencia C-789 de 2002. M. P. Rodrigo Escobar Gil, septiembre 24 de 2002.

Corte Constitucional. Sentencia C-623 de 2004, junio 29 de 2004.

Corte Constitucional. Sentencia C-754 de 2004, agosto 10 de 2004.

Corte Constitucional. Sentencia C-1024 de 2004. M. P. Rodrigo Escobar Gil, octubre 20 de 2004.

Corte Constitucional. Sentencia C-030 de 2009, enero 28 de 2009.
Corte Constitucional. Sentencia C-794 de 2009, noviembre 4 de 2009.

\section{Acción de Tutela}

Corte Constitucional. Sentencia T-235 de 2002, abril 4 de 2002.

Corte Constitucional. Sentencia T-1014 de 2004, octubre 15 de 2004.

Corte Constitucional. Sentencia T-818 de 2007, octubre 4 de 2007.

Corte Constitucional. Sentencia T-180 de 2008, febrero 22 de 2008.

Corte Constitucional. Sentencia T-347 de 2008, abril 17 de 2008.

Corte Constitucional. Sentencia T-398 de 2008, abril 24 de 2008.

Corte Constitucional. Sentencia T-168 de 2009. M. P. Humberto Antonio Sierra, marzo 18 de 2009.

Corte Constitucional. Sentencia T-449 de 2009, julio 9 de 2009.

Corte Constitucional. Sentencia T-566 de 2009, agosto 6 de 2009.

Corte Constitucional. Sentencia T-165 de 2010, marzo 8 de 2010.

Corte Constitucional. Sentencia T-320 de 2010. M. P. Nilson Pinilla Pinilla, mayo 6 de 2010. 
Corte Constitucional. Sentencia T-351 de 2010, mayo 11 de 2010.

Corte Constitucional. Sentencia T-583 de 2010, julio 22 de 2010.

Corte Constitucional. Sentencia T-618 de 2010, agosto 5 de 2010.

Corte Constitucional. Sentencia T-064 de 2011, febrero 4 de 2011.

Corte Constitucional. Sentencia T-232 de 2011. M. P. Nilson Pinilla Pinilla, marzo 31 de 2011.

Corte Constitucional. Sentencia T-317 de 2011. M. P. Jorge Iván Palacio Palacio, mayo 4 de 2011.

Corte Constitucional. Sentencia T-335 de 2011, mayo 4 de 2011.

Corte Constitucional. Sentencia T-572 de 2011, julio 21 de 2011.

\section{Acción de Unificación}

Corte Constitucional. Sentencia SU-062 de 2010. M. P. Humberto Antonio Sierra, febrero 3 de 2010.

Corte Constitucional. Sentencia SU-065 de 2010. M. P. Luis Ernesto Vargas Silva, febrero 4 de 2010.

Corte Constitucional. Acción de unificación SU-062 de 2010, febrero 3 de 2010.
Corte Constitucional. Sentencia SU-130 de 2013, marzo 13 de 2013.

\section{Acción Pública de Inconstitucionalidad}

Acosta, O. L. \& Ayala, U. (2001). Reformas pensionales y costos fiscales en Colombia. Santiago de Chile: Naciones Unidas.

Clavijo, S. \& Vera, A. (2010). Los desafíos fiscales de Colombia 2010-2014. Recuperado de http://anif.co/sites/default/files/uploads/ Anif-Fiscal0610.pdf

Congreso de la República. Ley 100 de 1993, Por la cual se crea el sistema de seguridad social integral y se dictan otras disposiciones.

Congreso de la República. Ley 797 de 2003, Por la cual se reforman algunas disposiciones del sistema general de pensiones previsto en la Ley 100 de 1993 y se adoptan disposiciones sobre los Regímenes Pensionales exceptuados y especiales.

Congreso de la República. Ley 1328 de 2009, Por la cual se dictan normas en materia financiera, de seguros, del mercado de valores y otras disposiciones.

Consejo de Estado, Sala de lo Contencioso Administrativo. Fallo (2011, abril de 2011). Sentencia 6 de abril de 2011, radicación 1101-03-25-00, 2007-00054-00 1995-2.

Corte Constitucional. Sentencia C-086 de 2002, febrero 13 de 2002. 
Decreto 3800 de 2003, Por el cual se reglamenta el literal e) del artículo 13 de la Ley 100 de 1993, modificado por el artículo $2^{\circ}$ de la Ley 797 de 2003. Presidente de la República (2003).

Decreto 3995 de 2008, Por el cual se reglamentan los artículos 12, 13 y 16 de la Ley 100 de 1993. Presidente de la República (2008).

Holzmann, R., Palmer, E. \& Uthoff, A. (2008). Fortalecer los sistemas pensionales latinoamericanos, cuentas individuales por reparto ( $1^{\text {a }}$ ed.). Bogotá: Banco Mundial; Cepal Mayol Ediciones.

Lora, E. \& Pagés, C. (2000). Hacia un envejecimiento responsable: Las reformas de los sistemas de pensiones en América Latina. Cuadernos económicos de ICE, 65, 283-324.

Mesa-Lago, C. (2004). Evaluación de un cuarto de siglo de reformas estructurales de pensiones en América Latina. Revista de la Cepal, 84 , pp. 59-82.
Superintendencia Financiera de Colombia. Circular Externa 006 de 2011, Traslado de régimen pensional en los términos de la Sentencia SU-062 de 2010 de la Corte Constitucional.

Uprimny, R. \& Guarnizo, D. (2008). ¿Es posible una dogmática adecuada sobre la prohibición de regresividad? Un enfoque desde la jurisprudencia constitucional colombiana. Recuperado de http://dejusticia.org/interna.php?id_tipo_publicacion=2\&id_publicacion $=180$

Uprimny, R. \& Rodríguez, C. A. (2005). Constitución y modelo económico en Colombia: hacia una discusión productiva entre la economía y el Derecho. Recuperado de http://www.dejusticia.org/index. php? modo=interna\&tema=derechos_ sociales\&publicacion $=178$

Vinueza, Á. P. G. (2012). Sostenibilidad fiscal y principios en el Estado Social de Derecho. Criterio Jurídico, 12(1), 79-126. 
